\title{
Cardiovascular effects of the aqueous extract from Caesalpinia ferrea: Involvement of ATP-sensitive potassium channels
}

\author{
Igor A.C. Menezes, Ítalo J.A. Moreira, Adriana A. Carvalho, \\ Angelo R. Antoniolli, Márcio R.V. Santos * \\ Departamento de Fisiologia, Laboratório de Farmacologia Cardiovascular, Universidade Federal de Sergipe, Av. Marechal Rondon, \\ S/N, Rosa Elze, CEP 49100-000, São Cristóvão, SE, Brazil
}

Received 9 January 2007; received in revised form 8 March 2007; accepted 30 March 2007

\begin{abstract}
Caesalpinia ferrea is a plant very used in the folk medicine for treatment of several diseases, such as diabetes. This study investigated the cardiovascular effects of the aqueous extract from stem bark of $C$. ferrea (AECF). In non-anesthetized rats, AECF (10, 20, 40, $60 \mathrm{and} 80 \mathrm{mg} / \mathrm{kg}$; i.v.) induced hypotension ( $-9 \pm 1 ;-12 \pm 1 ;-14 \pm 1 ;-20 \pm 3$ and $-51 \pm 6 \%$; respectively) and tachycardia $(6 \pm 1 ; 8 \pm 1 ; 12 \pm 2 ; 14 \pm 2$ and $26 \pm 3 \%$; respectively). Hypotension was not affected after atropine or L-NAME. Furthermore, AECF ( $40 \mathrm{mg} / \mathrm{kg})$ induced atrioventricular block and extrasystoles, which was not affected after atropine. In intact rings of the rat mesenteric artery, AECF $(0.001-30 \mathrm{mg} / \mathrm{ml}, n=6)$ induced relaxations of phenylephrine tonus $($ Emax $=110 \pm 4 \%)$, which was not changed after the removal of endothelium (Emax $=113 \pm 9 \%)$. In rings without endothelium pre-contracted with $\mathrm{KCl}$ $80 \mathrm{mM}$, phenylephrine plus $\mathrm{KCl} 20 \mathrm{mM}$ or phenylephrine plus glibenclamide, the curve to $\mathrm{AECF}$ was significantly attenuated (Emax $=24 \pm 4 \%, 70 \pm 5 \%$ and $62 \pm 7 \%$, respectively, $n=6$ ), but was not affected in the presence of tetraethylammonium or 4 -aminopyridine $($ Emax $=125 \pm 15 \%$ and $114 \pm 7 \%$, respectively, $n=6$ ). These results demonstrate that AECF induces hypotension associated to tachycardia; however, in dose of $40 \mathrm{mg} / \mathrm{kg}, \mathrm{AECF}$ induces transient bradyarrhythmias. Furthermore, AECF induces vasodilatation in rat mesenteric artery which appears to be mediated by ATP-sensitive $\mathrm{K}^{+}$ channel openings.
\end{abstract}

(C) 2007 Elsevier Inc. All rights reserved.

Keywords: Caesalpinia ferrea; Aqueous extract; Cardiovascular effect; ATP-sensitive $\mathrm{K}^{+}$channel; Rat

\section{Introduction}

The use of medicinal plants for the treatment of human diseases has increased considerably worldwide (Cirigliano and Sun, 1998). In some regions, like South Asia, plants are the major source of drugs, while in other regions such as Latin and North America, the concurrent use of traditional forms of medical care and herbal remedies is very common. In the United States, many patients who regularly take prescription medication reported the concurrent use of herbal products (Eisenberg et al., 1998).

Many herbal remedies have been popularly used for the treatment of diseases that produce harmful effects to the heart

Abbreviations: AECF, Aqueous extract of Caesalpinia ferrea; MAP, Mean arterial pressure; HR, Heart rate.

* Corresponding author. Tel.: +55 7932105 6645; fax: +55 7921056474 .

E-mail address: marcio@infonet.com.br (M.R.V. Santos). and the blood vessels such as hypertension, atherosclerosis and diabetes mellitus. However, only some of these plants have their effectiveness, safety and mechanism of action confirmed (Vora and Mansoor, 2005). Furthermore, herbal products can produce interactions that may increase or decrease the pharmacological and toxicological effects of traditional drugs used to treat cardiovascular diseases (Fugh-Berman, 2000). Because of these trends, many reports have evaluated the effects of several medicinal plants on the cardiovascular system. Such studies have investigated possible beneficial and/or side effects of herbal products in order to develop a scientific basis for their therapeutic application.

Caesalpinia ferrea Mart (Leguminosae), popularly known as "pau-ferro" or "jucá", is a large tree that grows abundantly in Brazil (Bragança, 1996). Some of its described properties include antiulcerogenic (Bachi et al., 1995), anti-inflammatory (Carvalho et al., 1996) and cancer chemopreventive (Nakamura 
et al., 2002). In Brazil, the tea of the stem bark of C. ferrea has been commonly used in the folk medicine for the treatment of diabetes mellitus (Bragança, 1996).

A preliminary phytochemical screening of hydroalcoholic extract of the stem bark and leaves demonstrated the presence of flavonoids, saponins, tanins, coumarins, steroids and phenolic compounds (Gonzalez et al., 2004).

Considering that any pharmacological study relating the activity of this plant on the rat cardiovascular system was found in the literature, this work aimed to evaluate the effects of C. ferrea on the arterial pressure, heart rate, electrical cardiac and vasorelaxant activities in rats.

\section{Materials and methods}

\subsection{Drugs}

The drugs used were: acetylcholine chloride (ACh), Lphenylephrine (Phe), Nó-nitro-L-arginine methyl ester hydrochloride (L-NAME), atropine sulphate (ATROP), 4-aminopyridine (4-AP), glibenclamide (GLIB) (All from SIGMA), sodium thiopental (CRISTÁLIA) and heparin sodium salt (ARISTON).

\subsection{Animals}

Male Wistar normotensive rats $(200-300$ g) were used for all of experiments. Animals were housed under conditions of controlled temperature $\left(25 \pm 1^{\circ} \mathrm{C}\right)$ and lighting (lights on: 06:0018:00 h) and had free access to food and tap water. All procedures described in the present work were approved by the Animal Research Ethics Committee of the Universidade Federal de Sergipe, Brazil (Protocol number 92/2006).

\subsection{Plant material and extraction}

C. ferrea was collected in the metropolitan region of Aracaju in the Brazilian state of Sergipe and identified by the Biology Department at the Universidade Federal de Sergipe. A voucher specimen was deposited in the Herbarium of the Biology Department at the Universidade Federal de Sergipe under identification code ASE 08633. The aqueous extract of $C$. ferrea (AECF) was obtained from its dried stem bark ( $80 \mathrm{~g}$ of powder) by an infusion with distilled water $\left(1 \mathrm{l} / 100{ }^{\circ} \mathrm{C}\right)$ followed by filtration. The filtrate was lyophilized (aqueous extract yield $10.8 \%$ ) and stored at $4{ }^{\circ} \mathrm{C}$. When required, the extract was dissolved in a saline solution for in vivo experiments or nutritive solution for in vitro experiments at desired concentrations just before use.

\subsection{Measurement of blood pressure and heart rate in non- anesthetized rats}

For measurement of the mean arterial pressure (MAP) and heart rate (HR), rats were anesthetized with sodium thiopental (45 mg/kg i.p.). Polyethylene catheters were inserted into the abdominal aorta via left femoral artery for pressure recordings and into the lower vena cava via left femoral vein for the administration of drugs. Both catheters were filled with heparinized saline and led under skin to exit between the scapulae. After $24 \mathrm{~h}$ of the surgery, rats were placed in large individual cages and experiments were performed in non-anesthetized rats.

The arterial catheter was connected to a pre-calibrated pressure transducer (Edwards Lifescience, Irvine, CA, USA) and pressure outputs were recorded in an amplifier-recorder (BioData, Model BD-01, PB, Brazil) connected to a personal computer equipped with an analog-to-digital converter board (BioData, PB, Brazil). For each cardiac cycle, the computer calculated the MAP and pulse interval (referred to as heart rate).

\subsection{AECF effect on mean arterial pressure and heart rate in non-anesthetized rats}

After the hemodynamics parameters had stabilized, MAP and HR were recorded before (baseline values) and after administration of the randomized doses of $\operatorname{AECF}(10,20,40,60$ and $80 \mathrm{mg} / \mathrm{kg}$; i.v.). Dose-response curves were then obtained. Successive injections were separated by a time interval sufficient to allow full recovery of hemodynamics parameters.

Similar records were obtained separately after administration of atropine, a muscarinic cholinergic antagonist $(2 \mathrm{mg} / \mathrm{kg}$; i.v.; $15 \mathrm{~min}$ ) or L-NAME, a nitric oxide (NO) synthase inhibitor (20 mg/kg; i.v.; $30 \mathrm{~min})$.

\subsection{Electrocardiogram records (ECG) and simultaneous direct blood pressure measurements in anesthetized rats}

The animals were catheterized as previously described and maintained under anesthesia with sodium thiopental $(45 \mathrm{mg} / \mathrm{kg}$; i.v.). The cardiac electrical activity was monitored by using subcutaneous electrodes implanted in the superior and inferior members of the animals, then coupled to an ECG recorder in the DII derivation. Immediately after surgical procedure and cardiovascular parameters had stabilized, a single dose of AECF (40 $\mathrm{mg} / \mathrm{kg}$, i.v.) was administrated and MAP, HR and cardiac electrical activity were recorded. A similar record was obtained after treatment with atropine ( $2 \mathrm{mg} / \mathrm{kg}$; i.v.; $15 \mathrm{~min})$.

\subsection{Preparation of isolated rings of rat superior mesenteric artery}

Rats were killed by stunning and exsanguination. The superior mesenteric artery was removed, cleaned from connective tissue and fat and sectioned in rings (1-2 $\mathrm{mm}$ long), which were suspended by cotton threads in organ baths containing $10 \mathrm{ml}$ of Tyrode' s solution (Composition in $\mathrm{mM}: \mathrm{NaCl} 158.3, \mathrm{KCl} 4.0$, $\mathrm{CaCl}_{2} \cdot 2 \mathrm{H}_{2} \mathrm{O} 2.0, \mathrm{NaHCO}_{3} 10.0, \mathrm{C}_{6} \mathrm{H}_{12} \mathrm{O}_{6} 5.6, \mathrm{MgCl}_{2} \cdot 6 \mathrm{H}_{2} \mathrm{O}$ 1.05 and $\mathrm{NaH}_{2} \mathrm{PO}_{4} \cdot \mathrm{H}_{2} \mathrm{O} 0.42$ ), gassed with carbogenic mixture $\left(95 \% \mathrm{O}_{2}\right.$ and $\left.5 \% \mathrm{CO}_{2}\right)$ and maintained at $37{ }^{\circ} \mathrm{C}$ for isometric tension recordings. The stabilization period was of $1 \mathrm{~h}$ under a resting tension of $0.75 \mathrm{~g}$. During this time the solution was changed every $15 \mathrm{~min}$, to prevent the accumulation of metabolites. The isometric tension was recorded through a force transducer (Gould, Model GM2, USA) coupled to an amplifierrecorder (Gould, USA). Endothelium was removed by gently 

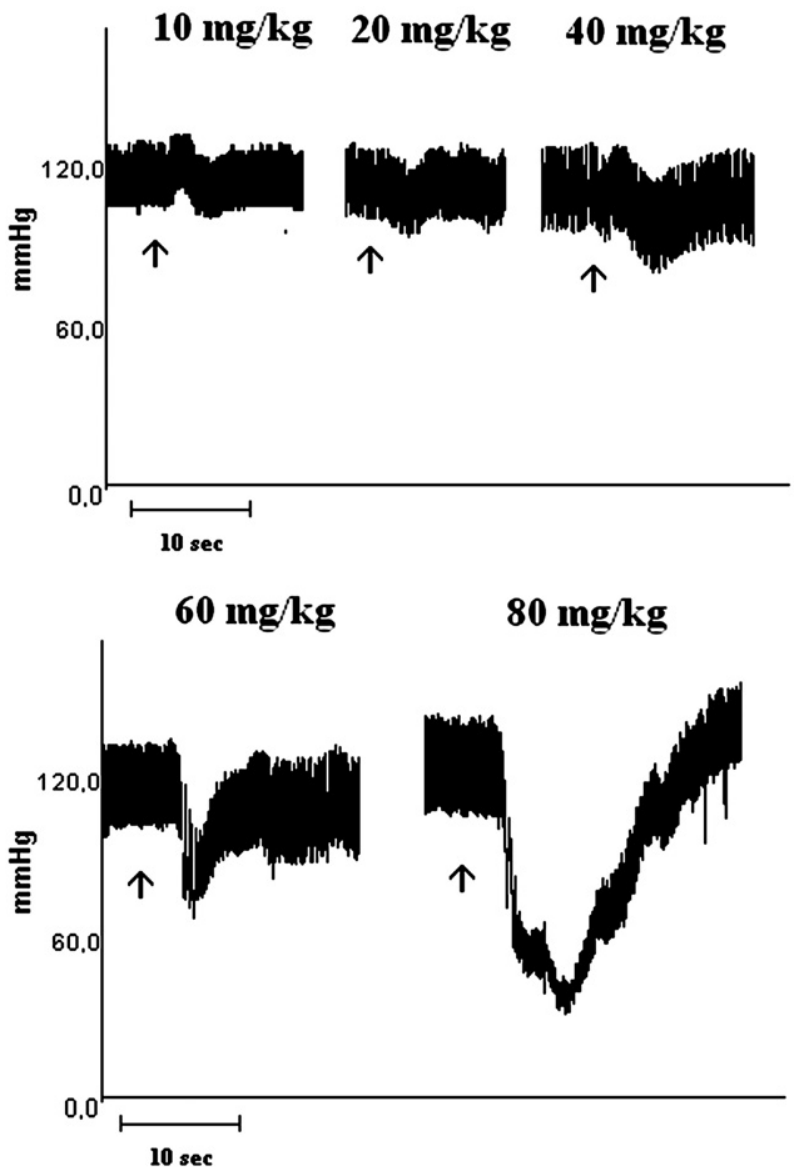

Fig. 1. Original trace showing the effects of aqueous extract of Caesalpinia ferrea (AECF) $(10,20,40,60$ and $80 \mathrm{mg} / \mathrm{kg}$, i.v.) on mean arterial pressure of a non-anesthetized normotensive rat. The arrows indicate the administration point.

rubbing the intimal surface of the vessels. The presence of functional endothelium was assessed by the ability of acetylcholine (ACh) $(10 \mu \mathrm{M})$ to induce more than $70 \%$ relaxation of pre-contracted vessels with Phe $(10 \mu \mathrm{M})$. The absence of the relaxation to ACh was taken as evidence that the vessel segments were functionally denuded of endothelium.

\subsection{AECF effect on Phe $(10 \mu \mathrm{M})$ induced tonus in isolated rat superior mesenteric artery rings with or without endothelium}

After stabilization period, two successive contractions of similar magnitude were induced with $10 \mu \mathrm{M}$ Phe in rings with or without endothelium. During the tonic phase of third contraction, different concentrations of AECF $(0.001 ; 0.003 ; 0.01$; $0.03 ; 0.1 ; 0.3 ; 1 ; 3 ; 10$ and $30 \mathrm{mg} / \mathrm{ml}$ ) were added cumulatively to the organ bath. The relaxations were measured by comparing the developed tension before and after the addition of AECF and expressed as percentage of relaxation from induced tonus.

\subsection{Effect of high concentration of $\mathrm{K}^{+}$on the AECF-induced vascular responses}

After the stabilization period, rings without endothelium were pre-contracted with $\mathrm{KCl} 80 \mathrm{mM}$ or $\mathrm{KCl} 20 \mathrm{mM}$ plus Phe and on the tonic phase, different concentrations of AECF
$(0.001 ; 0.003 ; 0.01 ; 0.03 ; 0.1 ; 0.3 ; 1 ; 3 ; 10$ and $30 \mathrm{mg} / \mathrm{ml})$ were added cumulatively to organ bath. The relaxations were measured as previously described.

2.10. Effect of 4-aminopyridine, tetraethylammonium and glibenclamide on the AECF-induced vascular responses

In this set of experiments, Phe-induced sustained contractions were obtained in preparations without endothelium incubated with 4-aminopyridine (4-AP/1 mM), a blocker of the voltage-activated $\mathrm{K}^{+}$channels $\left(\mathrm{K}_{\mathrm{V}}\right)$ (Lagaud et al., 1999), glibenclamide $(\mathrm{GLIB} / 10 \mu \mathrm{M})$ a blocker of ATP-sensitive $\mathrm{K}^{+}$ channels ( $\mathrm{K}_{\text {ATP}}$ ) (Lagaud et al., 1999), and tetraethylammonium (TEA/1 mM), in this concentration is selective blocker to $\mathrm{Ca}^{2+}$ activated $\mathrm{K}^{+}$channels $\left(\mathrm{K}_{\mathrm{Ca}}\right)$ (Langton et al., 1991; Lagaud et al., 1999), separately. Then, concentration-response curves to AECF were obtained. All blocking drugs were added $30 \mathrm{~min}$ before the contractions with Phe.

\subsection{Statistical analysis}

Values are expressed as mean \pm standard error mean (SEM). When appropriate, Student's $t$ test or one way ANOVA with
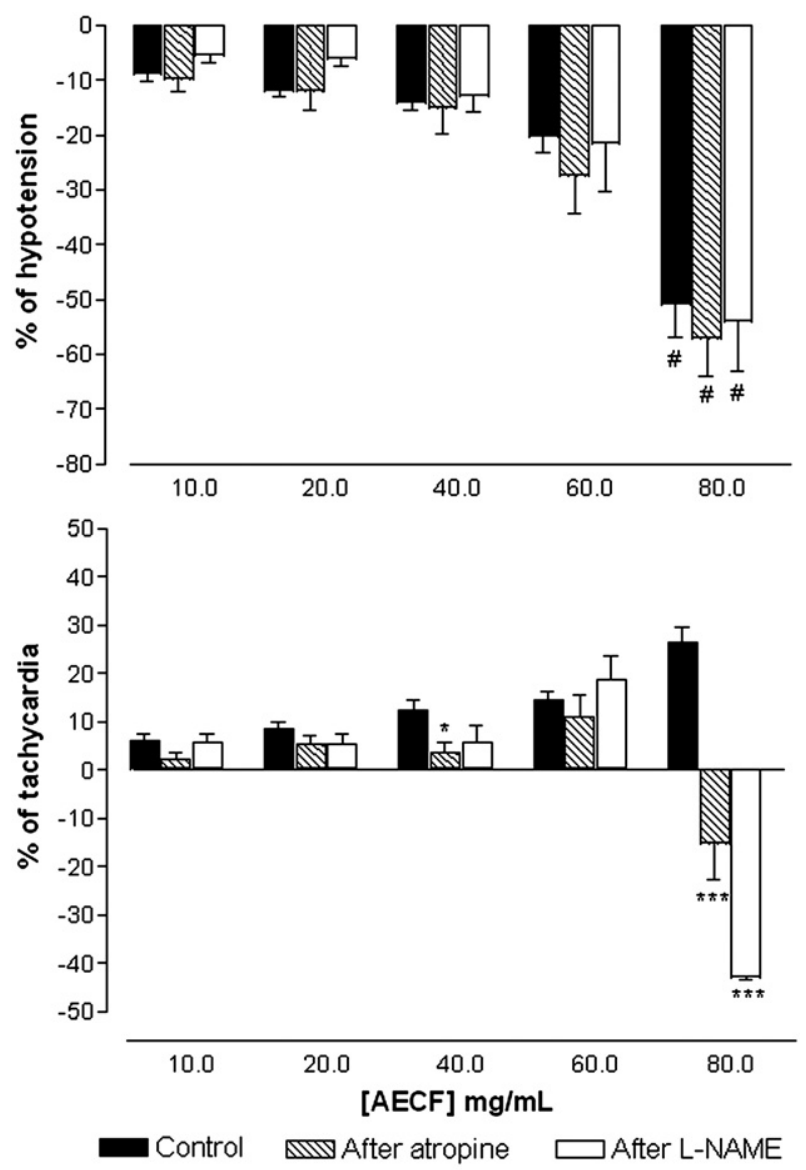

Fig. 2. Effect of aqueous extract of Caesalpinia ferrea (AECF) (10, 20, 40, 60 and $80 \mathrm{mg} / \mathrm{kg}$, i.v.) on mean arterial pressure and heart rate in non-anesthetized rats before (control) and after pretreatment with atropine $(2 \mathrm{mg} / \mathrm{kg}$, i.v.) or L-NAME $\left(20 \mathrm{mg} / \mathrm{kg}\right.$, i.v.). Values are mean $\pm \mathrm{SEM}$ of six experiments. ${ }^{*} p<0.05$ and ${ }^{* * *} p<0.001$ vs control; ${ }^{*} p<0.05$ vs $10,20,40$ and $60 \mathrm{mg} / \mathrm{kg}$. 


\section{Control}
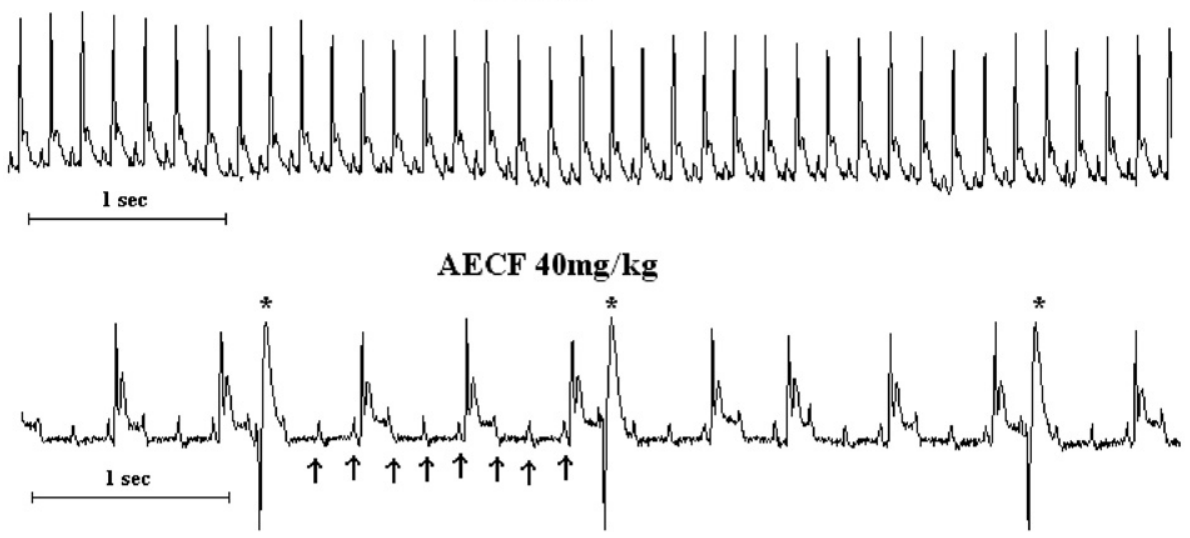

AECF $40 \mathrm{mg} / \mathrm{kg}$ plus atropine

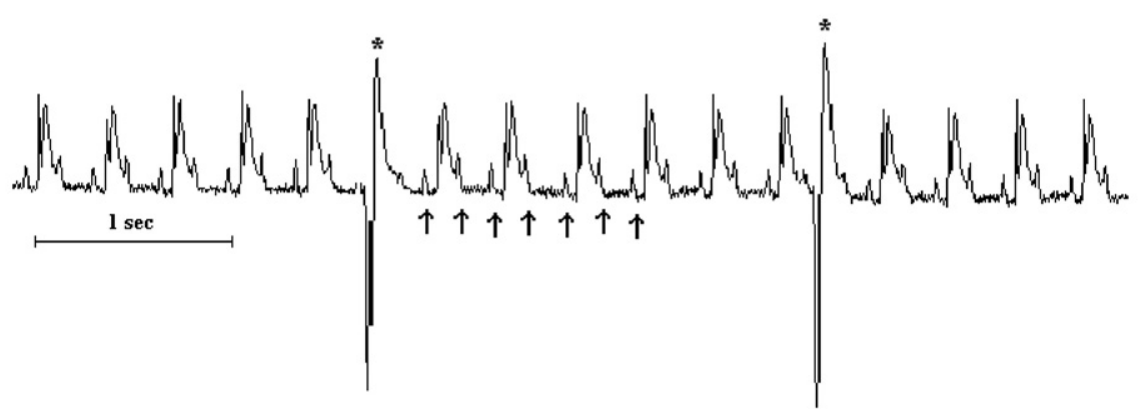

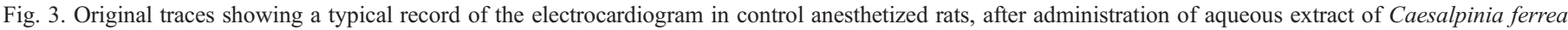

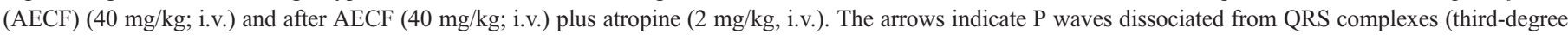
atrioventricular block) and the asterisks indicate extrasystoles.

Bonferroni post-test were conducted in order to evaluate the significance of differences between means. All statistical analyses were done by using Graph Pad Prism ${ }^{\mathrm{TM}}$ version 3.02 software.

\section{Results}

\subsection{AECF effect on MAP and HR in non-anesthetized rats}

In non-anesthetized normotensive rats, baseline MAP and HR values were $116 \pm 2 \mathrm{~mm} \mathrm{Hg}$ and $347 \pm 9 \mathrm{bpm}$ respectively. In these animals, the intravenous in bolus injections of AECF $(10,20,40$, 60 and $80 \mathrm{mg} / \mathrm{kg}$ ) induced a dose-dependent, intense and transitory hypotension $(-9 \pm 1 ;-12 \pm 1 ;-14 \pm 1 ;-20 \pm 3$ and $-51 \pm 6 \% ; n=9)$ associated with tachycardia $(6 \pm 1 ; 8 \pm 1 ; 12 \pm 2 ; 14 \pm 2$ and $26 \pm 3 \%$; $n=9$ ) (Figs. 1 and 2). The effects to each dose were fully recovered after $60 \mathrm{~s}$ (data not shown). In the doses of 40,60 and $80 \mathrm{mg} / \mathrm{kg}$, the AECF induced also transitory bradycardia $(-16 \pm 5 ;-18 \pm 7$ and $-24 \pm 9 \%$ ) prior to tachycardia.

\subsection{Effect of atropine or L-NAME on AECF-induced responses in non-anesthetized rats}

The baseline values of MAP $(115 \pm 4 \mathrm{~mm} \mathrm{Hg} ; n=6)$ were not affected after administration of atropine $(116 \pm 3 \mathrm{~mm} \mathrm{Hg})$, but were significantly increased after L-NAME $(158 \pm 7 \mathrm{~mm} \mathrm{Hg}$; $p<0.001)$. On the other hand, baseline values of HR $(333 \pm$
$19 \mathrm{~mm} \mathrm{Hg} ; n=6)$ were significantly increased after atropine $(445 \pm 10 ; p<0.01)$ and decreased after L-NAME $(297 \pm 13 \mathrm{bpm}$; $p<0.05$ ).

As showed in Fig. 2, the hypotensive effect was not changed in rats pretreated with atropine or L-NAME. However both treatments were able to potentiate the bradycardic effect induced by the dose of $80 \mathrm{mg} / \mathrm{kg}$ of AECF, which died $75 \%$ of animals after $7 \mathrm{~min}$.

\subsection{AECF effect on the ECG records in anesthetized rats}

In all animals tested ( $n=4)$, a single dose of $40 \mathrm{mg} / \mathrm{kg}$ of AECF (i.v.), induced transitory third-degree atrioventricular block and extrasystoles, which were not affected after pretreatment with atropine (Fig. 3). This dose was chosen because it was the lower dose that produced bradycardic effect prior to tachycardia. Furthermore, the hypotensive effect induced by dose of $40 \mathrm{mg} / \mathrm{kg}$ was not significantly different of that obtained in non-anesthetized rats $(-14 \pm 1 \% ; n=9$ versus $-22 \pm 5 \%, n=5)$.

\subsection{AECF effect on isolated rings of rat superior mesenteric artery}

In isolated rings of the superior mesenteric artery with intact endothelium, AECF $(0.001 ; 0.003 ; 0.01 ; 0.03 ; 0.1 ; 0.3 ; 1 ; 3 ; 10$ and $30 \mathrm{mg} / \mathrm{ml}$ ) induced concentration-dependent relaxations of tonus induced by $10 \mu \mathrm{M}$ of Phe tonus (Emax $=110 \pm 4 \%, n=6$ ), 
which was not significantly affected after removal of endothelium (Emax $=113 \pm 9 \%, n=6)$ (Fig. 4a). In endotheliumdenuded rings pre-contracted with $80 \mathrm{mM}$ of $\mathrm{KCl}$ or Phe plus $\mathrm{KCl} 20 \mathrm{mM}$, the AECF-induced vasorelaxations was significantly $(p<0.05)$ attenuated $(\operatorname{Emax}=24 \pm 4 \%$ and $70 \pm 5 \%, n=6$, respectively) (Fig. 4b).

In endothelium-denuded rings $(n=7)$, the incubation with $10 \mu \mathrm{M}$ of GLIB was capable of attenuated AECF-induced vasorelaxations $(\operatorname{Emax}=62 \pm 7 \% ; p<0.001)$ (Fig. 5b). On the other hand, in the presence of $1 \mathrm{mM}$ of TEA or $1 \mathrm{mM}$ of 4-AP the vasorelaxations were not significantly affected (Emax $=125 \pm 15 \%$ and $114 \pm 7 \%$, respectively) (Fig. 5a).

\section{Discussion}

We decided to evaluate firstly the AECF effects on the cardiovascular parameters in non-anesthetized rats in order to
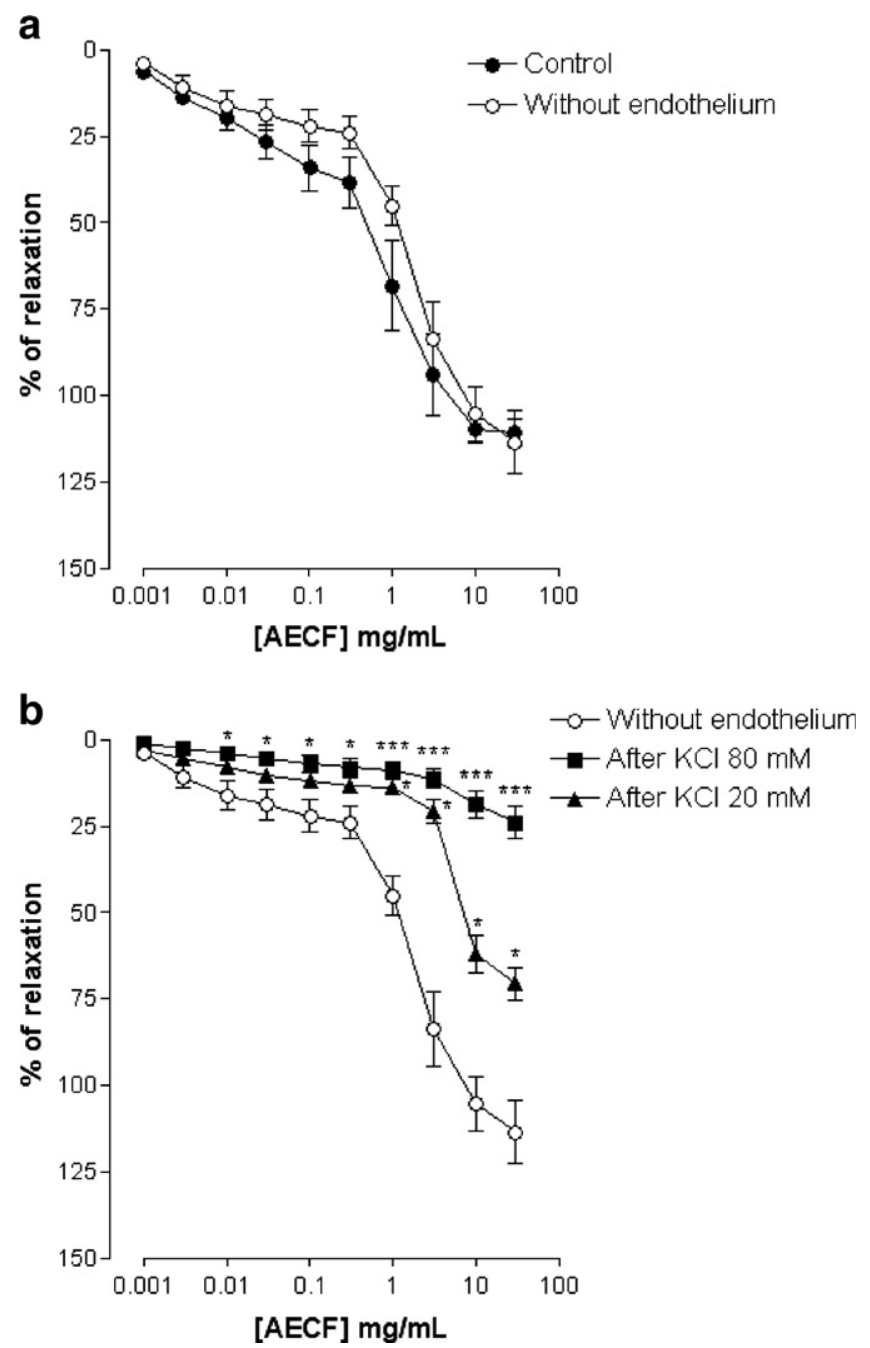

Fig. 4. Vasorelaxant effect of aqueous extract of Caesalpinia ferrea (AECF) $(0.001$; $0.003 ; 0.01 ; 0.03 ; 0.1 ; 0.3 ; 1 ; 3 ; 10$ and $30 \mathrm{mg} / \mathrm{ml}$, cumulatively) in rings of rat superior mesenteric artery: (a) pre-contracted with Phe $(10 \mu \mathrm{M})$ in the control condition (with endothelium) and after removal of endothelium (without endothelium); (b) without endothelium pre-contracted with Phe (Without endothelium), with $\mathrm{KCl} 80 \mathrm{mM}$ and with Phe after $\mathrm{KCl} 20 \mathrm{mM}$. Values are mean $\pm \mathrm{SEM}$ of six experiments. ${ }^{*} p<0.05$ and ${ }^{* * *} p<0.001$ vs without endothelium.
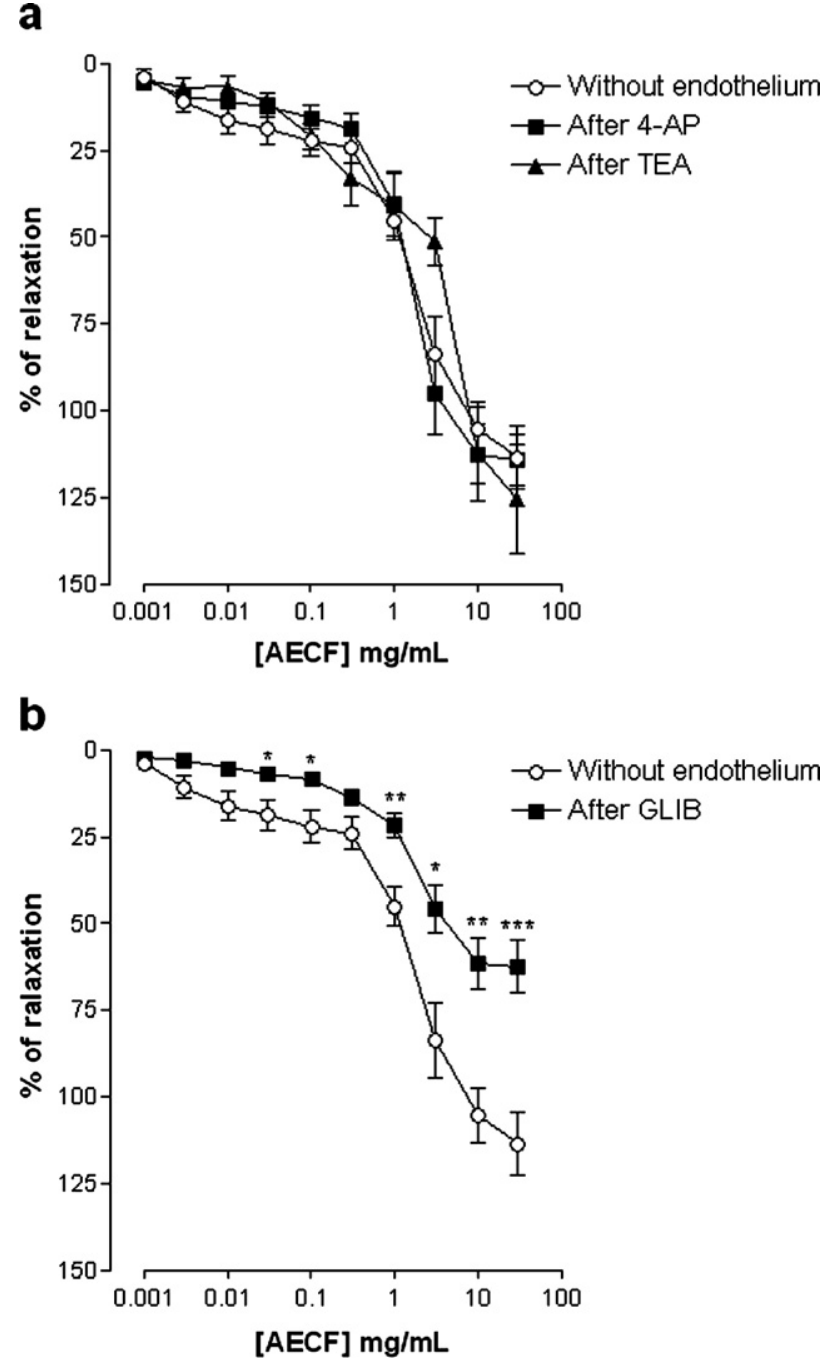

Fig. 5. Vasorelaxant effect of aqueous extract of Caesalpinia ferrea (AECF) $(0.001 ; 0.003 ; 0.01 ; 0.03 ; 0.1 ; 0.3 ; 1 ; 3 ; 10$ and $30 \mathrm{mg} / \mathrm{ml}$, cumulatively) in rings of rat mesenteric artery without endothelium pre-contracted with Phe $(10 \mu \mathrm{M})$ : (a) in control condition (without endothelium), after $1 \mathrm{mM}$ of TEA or $1 \mathrm{mM}$ of 4-AP; (b) in control condition (without endothelium) or after $10 \mu \mathrm{M}$ of GLIB. Values are mean \pm SEM of six experiments. ${ }^{*} p<0.05,{ }^{* *} p<0.01$ and $* * * p<0.001$ vs without endothelium.

avoid the influences of anesthesia and post-surgical stress (Smith and Hutchins, 1980; Fluckiger et al., 1985). In these animals, AECF induced intense hypotension associated with tachycardia. In addition, AECF-induced bradycardia prior to tachycardia in the higher doses.

As is well established in the literature, vascular tone of the arterial bed underlies the maintenance of peripheral resistance in the circulation (Mulvany and Aalkjaer, 1990) and is the major contributor to the control of blood pressure (White et al., 1996). Furthermore, in most vascular beds, the activation of muscarinic receptors in the endothelial cells induces vasorelaxation by release of endothelium-derived relaxant factors (EDRFs), including NO (Furchgott and Zawadzki, 1980; Moncada and Higgs, 1993). In order to verify the role of muscarinic receptors in hypotensive response induced by AECF, we performed experiments in the animals pretreated with atropine, a non- 
selective antagonist of these receptors. Under this condition, the hypotensive response was not significantly changed, suggesting that AECF appears not be acting via muscarinic receptor activation. To determine if this effect could involve the release of NO by an independent way of the muscarinic activation, we performed experiments with L-NAME, an inhibitor of the NO synthase. Similarly to atropine, L-NAME was also not capable of significantly changing AECF-induced hypotension, suggesting that $\mathrm{NO}$ appears not be participating of this effect.

In a set of in vitro experiment using rings from the rat superior mesenteric artery, we verified if hypotensive response could be due to a decrease in peripheral vascular resistance caused by a possible vasorelaxation. In these preparations, AECF induced vasorelaxation in a concentration-dependent manner of Phe-induced tonus.

In order to investigate the participation of the endothelium in the vasorelaxant response induced by the AECF, we performed experiments in the absence of functional endothelium. In this condition, the response induced by AECF was not affected (Fig. 4a). These in vitro findings are in agreement with those obtained in the in vivo experiments, which demonstrated that hypotension induced by the AECF appears not to be mediated by muscarinic receptors or NO.

Potassium channels are the dominant ion conductive pathways in vascular muscle cells and their activity importantly contributes to determination and regulation of membrane potential and vascular tone (Nelson and Quayle, 1995; Jackson, 2000). The electrochemical gradient for $\mathrm{K}^{+}$ions is such that the opening of $\mathrm{K}^{+}$channels results in the diffusion of this cation out of the cells and hyperpolarization. This effect closes voltagegated $\mathrm{Ca}^{2+}$ channels and leads to vasodilatation (Jackson, 2000). In order to investigate the involvement of $\mathrm{K}^{+}$channels in the vasorelaxant effect of AECF, we performed experiments in the presence of high concentrations of $\mathrm{K}^{+}$, as 20 or $80 \mathrm{mM}$. These procedures partially prevent the efflux of $\mathrm{K}^{+}$through the membrane and, therefore inhibit the relaxations mediated by the opening of $\mathrm{K}^{+}$channels (Campbell et al., 1996). Under these conditions, the vasorelaxant effect of AECF was significantly attenuated in both experimental protocols (Fig. 4b), suggesting an involvement of $\mathrm{K}^{+}$channels in this response.

Four major types of $\mathrm{K}^{+}$channels are involved in the vascular tone regulation: the large conductance $\mathrm{Ca}^{2+}$-activated $\mathrm{K}^{+}$channels $\left(\mathrm{BK}_{\mathrm{Ca}}\right)$, the small conductance $\mathrm{Ca}^{2+}$-activated $\mathrm{K}^{+}$channels $\left(\mathrm{SK}_{\mathrm{Ca}}\right)$, voltage-activated $\mathrm{K}^{+}$channels $\left(\mathrm{K}_{\mathrm{v}}\right)$ and ATP-sensitive $\mathrm{K}^{+}$channels $\left(\mathrm{K}_{\mathrm{ATP}}\right)$ (Jackson, 2000). To identify the type of $\mathrm{K}^{+}$ channel that could be involved in the vasorelaxation, we incubated endothelium-denuded preparations with 4-AP, TEA or GLIB. This set of experiments revealed that AECF-induced vasorelaxations were significantly attenuated after GLIB (Fig. 5b), but were not affected after TEA or 4-AP (Fig. 5a), suggesting that the effect induced by AECF is somehow recruiting $\mathrm{K}_{\text {ATP }}$ channels.

Nevertheless, hypotensive response, in doses of 40, 60 and mainly $80 \mathrm{mg} / \mathrm{kg}$, appears not to be exclusively due to a decrease in the peripheral vascular resistance, since that tachycardic response was preceded by a transient bradycardia. In order to best evaluate this effect, we performed ECG recordings during the administration of AECF. In these experiments, the AECF was capable of inducing transitory thirddegree atrioventricular block and extrasystoles. These bradyarrhythmias seem not to be due to a vagal stimulation or direct activation of cardiac muscarinic receptor, since the effects were not affected by pretreatment with atropine. It is well known that complex arrhythmias as these, can produce a decrease in cardiac output due to a reduction of the number of effective heart beats (Mayer and Kaelin, 1972; Sowton, 1991) contributing to lower the blood pressure.

The literature shows that heart conduction delay and block can be produced by substances with characteristic profile of potassium channels activators such as pinacidil and nicorandil (Gotanda et al., 1988; Damiano et al., 1993). These substances, which are also vasodilators, can prolong in large doses the conduction time of sinoatrial and atrioventricular nodal due to an increase in membrane potassium conductance in cardiac muscle cells (Gotanda et al., 1988). Then, it is possible to hypothesize that the arrhythmogenic effects induced by AECF could be due to the activation of potassium channels in the cardiac myocytes. However, further experiments are necessary to clearly elucidate this assumption.

In Brazil, many diabetic patients with associated cardiovascular diseases, daily drink the tea of $C$. ferrea and this study demonstrated possible benefits of this plant on the cardiovascular system. Recent reports have showed the potential clinical use of potassium channels openers in the hypertension, vasculopathy (Sobey, 2001; Jahangir and Terzic, 2005) and myocardial ischemia (Richer et al., 1990). However, potassium channel openers also could be harmful to diabetes treatment because they produce hyperglycemia by inhibition of insulin release in pancreatic $\beta$-cells (Aguilar-Bryan et al., 2001).

On the other hand, Guldstrand et al. (2002) have demonstrated that potassium channel openers, through pancreatic $\beta$-cell hyperpolarization, can improve the insulin release pattern in type- 2 diabetes and Carr et al. (2003) have demonstrated that these openers also can reduce basal hyperglycemia, improve glucose tolerance, and reduce hyperinsulinemia during oral glucose tolerance test and improve insulin secretory responsiveness in a model of type-2 diabetes.

We also found possible risks of the uncontrolled use of this plant due to its arrhythmogenic effect, mainly because various therapeutic drugs could potentiate the risk of fatal arrhythmias like beta-blockers or calcium-blockers (Rang et al., 2003). In this study, the interaction of the AECF with L-NAME or atropine could explain the mortality of many animals after the administration of the dose of $80 \mathrm{mg} / \mathrm{kg}$, since the atrioventricular block and other arrhythmias can be potentiated or produced by these drugs (Murashev et al., 2003; Bernheim et al., 2004).

\section{Conclusion}

In conclusion, the present study, by using in vivo and in vitro approaches, demonstrates that AECF induces hypotension associated to tachycardia in normotensive rats, however, in dose of $40 \mathrm{mg} / \mathrm{kg}$, AECF induces transient bradyarrhythmias. Furthermore, AECF induces vasodilatation in rat mesenteric 
artery which appears to be mainly mediated by ATP-sensitive $\mathrm{K}^{+}$channel openings. This plant seems to have a potential clinical use for cardiovascular diseases, however, further studies are necessary to evaluate its safety and therapeutic margin before the human use.

\section{Acknowledgements}

We thank Mr Osvaldo Andrade Santos for the technical support. This work was supported by grants from CAPES and FAPITEC-SE, Brazil.

\section{References}

Aguilar-Bryan, L., Bryan, J., Nakazaki, M., 2001. Of mice and men: K(ATP) channels and insulin secretion. Recent Prog. Horm. Res. 56, 47-68.

Bachi, E.M., Sertie, J.A.A., Villa, N., Katz, H., 1995. Antiulcer action and toxicity of Styrax camporum and Caesalpinia ferrea. Planta Med. 61, 204-207.

Bernheim, A., Fatio, R., Kiowski, W., Weilenmann, D., Rickli, H., Rocca, H.P., 2004. Atropine often results in complete atrioventricular block or sinus arrest after cardiac transplantation: an unpredictable and dose-independent phenomenom. Transplantation 77, 1181-1185.

Bragança, L.A.R., 1996. Plantas Medicinais Antidiabéticas. EDUFF press, Niterói, RJ, p. 172.

Campbell, W.B., Gebremedhin, D., Prait, P.F., Herder, D.R., 1996. Identification of epoxyeicosatrienoic acids as endothelium-derived hyperpolarizing factors. Circ. Res. 78, 415-423.

Carr, R.D., Brand, C.L., Bodvarsdottir, T.B., Hansen, J.B., Sturis, J., 2003. NN414, a SUR1/Kir6.2-selective potassium channel opener, reduces blood glucose and improves glucose tolerance in the VDF Zucker rat. Diabetes 52, 2513-2518.

Carvalho, J.C.T., Teixeira, J.R.M., Souza, P.J.C., Bastos, J.K., Filho, D.S., Sarti, S.J., 1996. Preliminary studies of analgesic and anti-inflammatory properties of Caesalpinia ferrea crude extract. J. Ethnopharmacol. 53, 175-178.

Cirigliano, M., Sun, A., 1998. Advising patients about herbal therapies. JAMA 280, 1565-1566.

Damiano, B.P., Stump, G.L., Cheung, W.M., Salata, J.J., 1993. In vivo cardiac electrophysiologic effects of RWJ 29009, a new potassium-channel activator, in comparison to cromakalim and nicardipine. J. Cardiovasc. Pharmacol. 22, 146-152.

Eisenberg, D.M., Davis, R.B., Ettner, S.L., 1998. Trends in alternative medicine use in the United States. JAMA 280, 1569-1575.

Fluckiger, J.P., Sonnay, N., Boillat, N., Atkinson, J., 1985. Attenuation of the baroreceptor reflex by general anesthetic agent in normotensive rat. Eur. J. Pharmacol. 109, 105-109.

Fugh-Berman, A., 2000. Herb-drug interactions. Lancet 355, 134-138.

Furchgott, R.F., Zawadzki, J.V., 1980. The obligatory role of endothelial cells in the relaxation of arterial smooth muscle by acetylcholine. Nature 288, 373-376.

Gonzalez, F.G., Barros, S.B.M., Bachi, E.M., 2004. Atividade antioxidante e perfil fitoquímico de Caesalpinia ferrea MART. Braz. J. Pharm. Sci. 40 (supl 1), 79
Gotanda, K., Satoh, K., Taira, N., 1988. Is the cardiovascular profile of BRL 34915 characteristic of potassium channels activators? J. Cardiovasc. Pharmacol. 12, 239-246.

Guldstrand, M., Grill, V., Bjorklund, A., Lins, P.E., Adamson, U., 2002. Improved beta cell function after short-term treatment with diazoxide in obese subjects with type 2 diabetes. Diabetes Metab. 28, 448-456.

Jackson, W.F., 2000. Íon channels and vascular tone. Hypertension 35, 173-178.

Jahangir, A., Terzic, A., 2005. KATP channel therapeutics at the bedside. J. Mol. Cell. Cardiol. 39, 99-112.

Lagaud, G.J., Skarsgard, P.L., Laher, I., Van Breemen, C., 1999. Heterogeneity of endothelium-dependent vasodilation in pressurized cerebral and small mesenteric resistance arteries of the rat. J. Pharmacol. Exp. Ther. 290, $832-839$.

Langton, P.D., Nelson, M.T., Huang, Y., Standen, N.B., 1991. Block of calciumactivated potassium channels in mammalian arterial myocytes by tetraethylammonium ions. Am. J. Physiol. 260, H927-H934.

Mayer, G.G., Kaelin, P.B., 1972. Arrhythmias and cardiac output. Am. J. Nurs. 72, 1597-1600.

Moncada, S., Higgs, E.A., 1993. The L-ariginine-nitric oxide pathway. N. Engl. J. Med. 29, 2002-2012.

Mulvany, M.J., Aalkjaer, C., 1990. Structure and function of small arteries. Physiol. Rev. 70, 921-961.

Murashev, A.N., Rzhevskii, D.I., Korshunov, V.A., Lobanov, A.V., 2003. Arrhythmogenic effects of endothelin-1 under conditions of NO-synthase blockade with L-NAME in NMRI mice. Bull. Exp. Biol. Med. 135, 370-373.

Nakamura, E.S., Kurosaki, F., Arisawa, M., Mukainaka, T., Takayasu, J., Okuda, M., Tokuda, H., Nishino, H., Pastore, F., 2002. Cancer chemopreventive effects of a Brazilian folk medicine, Juca, on in vivo two-stage skin carcinogenesis. J. Ethnopharmacol. 81, 135-137.

Nelson, M.T., Quayle, J.M., 1995. Physiological roles and properties of potassium channels in arterial smooth muscle. Am. J. Physiol. 268, C799-C822.

Rang, H.P., Dale, M.M., Ritter, J.M., Moore, M.C., 2003. Pharmacology, 5th ed. Elsevier, United Kingdom.

Richer, C., Pratz, J., Mulder, P., Mondot, S., Giudicelli, J.F., Cavero, I., 1990. Cardiovascular and biological effects of $\mathrm{K}^{+}$channel openers, a class of drugs with vasorelaxant and cardioprotective properties. Life Sci. 47, 1693-1705.

Smith, T.L., Hutchins, P.M., 1980. Anaesthetic effects on hemodynamics os spontaneously hypertensive and Wistar-Kyoto rats. Am. J. Physiol. 238, H539-H544.

Sobey, C.G., 2001. Potassium channels function in the vascular disease. Arterioscler. Thromb. Vasc. Biol. 21, 28-38.

Sowton, E., 1991. Hemodynamic consequences of arrhythmias. J. Cardiovasc. Pharmacol. 17 (Supl 6), S20-S23.

Vora, C.K., Mansoor, G.A., 2005. Herbs and alternative therapies: relevance to hypertension and cardiovascular diseases. Curr. Hypertens. Rep. 7, 275-280.

White, R.M., Rivera, C.O., Davison, C.B., 1996. Differential contribution of endothelial function to vascular reactivity in conduit and resistance arteries from deoxycorticosterone-salt hypertensive rats. Hypertension 27, $1245-1253$ 